\title{
Effectiveness of Telescopic Advertisements Delivered via Personal Video Recorders
}

\section{NICHOLAS READING}

Rio Tinto

nick.reading@riotinto.com

\section{STEVEN BELLMAN}

Interactive Television

Research Institute,

Murdoch University

bellman@itri.tv

\section{DUANE VARAN}

Interactive Television

Research Institute,

Murdoch University

varan@itri.tv

\section{HUME WINZAR}

Griffith University h.winzar@griffith.edu.au

The advent of personal video recorders (PVRs) may alter existing patterns of television advertising viewing. Although much of this might be characterized by increased advertising avoidance, this article explores the potential for a new advertising model utilizing PVRs, "telescopic advertising," enabling viewers to access extended content associated with the advertising. The effectiveness of four telescopic advertisements is compared with advertisements for the same products using the traditional 30-second TV commercial format and the infomercial format. Across four product categories, using an Australian sample, telescopic advertisements achieved significantly higher attitude toward the advertisement, attitude toward the brand, and behavioral intentions.

Personal Video Recorders (PVRs) may significantly change the television advertising landscape. On one hand, PVRs empower viewers to more easily avoid TV advertising. At the same time, however, the additional functionality enabled by PVRs may result in new models of advertising, including "telescopic" advertising offering additional content on demand. This study, conducted in Australia, explored the potential effectiveness of telescopic advertisements.

In their simplest form, PVRs are essentially hard drives designed to store content delivered through television. A number of PVR solutions are available, offering a wide range of services including parallel recording (recording more than one channel at the same time), buffered viewing (enabling replay and fast forward during "live" TV), intelligent monitoring of viewing activity (facilitating automatic recording and recommending of programs), electronic program guides, showcasing (additional content prestored for triggered viewing), and many other services.

A threat commonly associated with PVRs has been their use to avoid advertising. Estimates of how many advertisements are by-passed by PVR households range from 72 percent (Friedman, 2002) to as high as 88 percent (Swain and Blustin, 2000). These measures tend to be based on self-report, however, and it is often not clear whether viewers avoid all advertisements, for example, or just some advertisements. Advertising avoidance rates probably vary considerably by product category. CNW Research (Friedman, 2002), for example, found that avoidance rates on the PVR were much higher for financial institution advertising than for beer advertisements ( 90 percent versus 32.7 percent).

Telescopic advertisements are a form of interactive TV advertising that allows the interested viewer to watch extended audio-visual advertising content, which can be arranged in a series of layers, allowing viewers to selectively drill deeper. This additional content can be downloaded to a PVR, either on demand or stored in advance until summoned by the viewer. Once stored (or "banked"), such content can be viewed repeatedly. Most PVRs also allow for program viewing to be buffered, so that when the extended advertising content finishes, viewers are returned to where they left without missing any content. Telescopic advertisements have been available on the TiVo platform as "showcase" advertisements since 2002 (Olsen and Shim, 2004). But do telescopic 


\section{A threat commonly associated with PVRs has been their} use to avoid advertising.

advertisements deliver higher advertising impact for those who interact with them? We tested whether telescopic advertisements outperformed two traditional advertising formats: the 30-second commercial and the long-format infomercial.

\section{LITERATURE REVIEW}

Although PVRs have captured the imagination of the popular press, few academic studies have explored these new devices and their potential impact. We first review evidence for the greater effectiveness of longer format TV commercials (which telescopic advertisements are) in comparison with the traditional 30-second format and then review the limited evidence so far for the superiority of including interactivity in advertising.

Longer form advertising provides advertisers with greater opportunity to substantiate arguments (Agee and Martin, 2001; Stanton and Burke, 1998). Longer advertisement formats also provide space for the inclusion of a product category message, useful when the target audience is unfamiliar with the category, and provide advertisers with execution and response options not available in shorter advertising formats (Agee and Martin, 2001; Chapman and Beltramini, 2000; Hawthorne, 1997; Singh, Balasubramanian, and Chakraborty, 2000; Singh and Cole, 1993). For example, Rossiter and Bellman (2005) estimate that increasing the length of a TV commercial from 30 to 60 seconds will increase the likelihood of attention from a 65 to 76 percent chance, and moreover, commercials 90 seconds or longer guarantee 100 percent of the audience will pay attention at some stage. However, it ap- pears that this is an "inverse- $U$ " effect, as advertising presentations decline in effectiveness beyond 15 minutes (Singh, Balasubramanian, and Chakraborty, 2000). As long as the total length of a telescopic advertisement is less than 15 minutes, it should outperform a traditional 30-second advertisement simply because it is longer.

Less certain is what difference the addition of a trivial element of interactivity, a click to request additional content, will make to advertising effectiveness. Apart from an extra 30 seconds in length, it is only this element of interactivity that separates our telescopic advertisements from the other traditional format we compared them to: long-format infomercials. Cognitive dissonance theory (Festinger, 1957) suggests that consumers will tend to consider the choices they make, such as requesting additional advertising content, as justified and important (Harmon-Jones and Mills, 1999; Oliver, 1997; Shultz, Léveillé, and Lepper, 1999). Also, interaction by its nature can motivate an individual to focus more attention toward a medium and thus to an advertised message (Ha and James, 1998; McMillan, Hwang, and Lee, 2003; Rosenfield, 1997). The likelihood of engagement with advertising content is greater if viewers are presented with choices, even the choice to take shortcuts through the material ( $\mathrm{Ha}$ and James, 1998; Harmon-Jones and Mills, 1999; Oliver, 1997; Shultz, Léveillé, and Lepper, 1999). In summary, these theories suggest that because a person chooses to engage in the interaction, this choice and the following interaction should enhance their subsequent exposure. Without choice and interactivity, a message of equal du- ration may not be perceived as important and may therefore be less effective. This implies that our infomercials, which are only 30 seconds shorter than our telescopic advertisements but do not require the consumer to click to see them, will be less effective than telescopic advertisements.

The measures of advertising effectiveness we used were those that many researchers have recommended: behavioral intention and its immediate antecedents, attitude toward the brand, and attitude toward the advertisement (Ajzen and Fishbein, 1977; Biel and Bridgwater, 1990; Blair and Rabuck, 1998; du Plessis, 1994; Gibson, 1983; Ross, 1984; Rossiter and Eagleson, 1994; Sutherland and Sylvester, 2000; Terry and O'Leary, 1995; Walker and Dubitsky, 1994). Because we used a semiforced exposure procedure, measures of attention were not appropriate, and furthermore there is often a low correlation between attention (usually measured by advertising recall) and persuasion (e.g., Gibson, 1983; Ross, 1984). Gibson (1983) and Rosenfield (1997) go even further to argue that advertising that draws attention to itself is less likely to be persuasive. But the evidence presented by Gibson (1983; Table 10) does not indicate a negative relationship, and it may well be that the longer advertisement duration and the "lean forward" mode of processing associated with telescopic advertisements lift performance on both these outcomes (du Plessis, 1994; Stewart, 1986).

In summary, we expect that telescopic advertisements, provided they are interacted with, should outperform traditional 30second advertisements and infomercials because they are longer and they include an element of interactivity:

H1: Telescopic advertisements will be more effective than traditional advertising formats in terms of: 
(a) attitude toward the advertisement $\left(A_{a d}\right)$, (b) attitude toward the brand $\left(\mathrm{A}_{\mathrm{b}}\right)$, and $(\mathrm{c})$ behavioral intentions (BI).

Because the number of interactors is likely to be less than the entire audience, we do not expect to find a superior effect of telescopic advertisements when interactors and noninteractors are aggregated together. All the interactive advertisements may do is allow those already persuaded by previous advertising (including the 30-second advertisement with the telescopic call-to-action) to "self-select" themselves, that is, identify themselves from the rest of the audience. The sample of interactors identified by this process would be very interested in the advertised product compared to the average consumer, while the sample of noninteractors would be very disinterested compared to the average consumer. But a sample that combined these interactors and noninteractors will probably be no different from a sample of average consumers.

We can control for this self-selection effect by measuring a consumer's involvement with the advertised product category (Buchholz and Smith, 1991; Ha and James, 1998; Petty, Cacioppo, and Schumann, 1983; Rosenfield, 1997). Product category involvement can be an enduring trait or temporarily elevated by situational factors, such as being "in the market" (Celsi and Olson, 1988; Mittal, 1989; Richins and Bloch, 1986; Vaughn, 1986). The well-established elaboration likelihood model (ELM) suggests that consumers who are more involved with an advertised category will be more motivated to process advertising content (Celsi and Olson, 1988; Higie, Feick, and Price, 1991; Mittal, 1989). In other words, category involvement should stimulate initial interest in paying attention to the advertising. We also need to control for spurious "lift" due to involvement when trying to gauge the efficacy of the advertisement itself. Ideally, we would control for individual differences by comparing pre- and postmeasures of advertising effectiveness. In our experiment, however, we used postmeasures only, so we control for involvement effects by including product category involvement as a covariate in our analyses. We expect to find a positive relationship between involvement and measures of advertising effectiveness, which we will in effect "subtract" from our main results so that are clearly due only to differences between advertisements:

H2: Higher levels of product category involvement will be associated with more favorable: (a) attitude toward the advertisement $\left(A_{a d}\right)$, (b) attitude toward the brand $\left(A_{b}\right)$, and (c) behavioral intentions (BI).

Product category involvement is also likely to moderate the effectiveness of telescopic advertisements. Very few lowinvolvement viewers would have the motivation to view additional content about a product category they care little about. Low-involvement viewers are less likely to be influenced by a telescopic advertisement because fewer of them will be exposed to all of its persuasive arguments. The semi-forced nature of our study is, however, likely to attenuate this self-selection effect of telescopic advertisements. The demand effects of the laboratory environment may generate telescopic advertisement click-through from participants who have low involvement with the advertised category. Cognitive dissonance theory (Festinger, 1957) suggests that these participants are likely to reconcile this dissonant behavior by attributing highly attractive ratings to the telescopic advertisement and the brand it is adver- tising. This implies that, in this study, telescopic advertisements are likely to be equally effective whether participants have low or high levels of product category involvement. In contrast, the effectiveness of traditional advertisements should increase in line with the main (covariate) effect of increasing product category involvement (in line with Hypothesis H2). Following Baron and Kenny (1986), we test for this moderating effect of involvement on the relative effectiveness of telescopic advertisements by examining the significance of the interaction effect between involvement and advertisement type:

H3: For telescopic advertisements seen in their entirety, participants with low and high involvement will have equally favorable: (a) attitude toward the advertisement $\left(\mathrm{A}_{\mathrm{ad}}\right)$, (b) attitude toward the brand $\left(\mathrm{A}_{\mathrm{b}}\right)$, and $(\mathrm{c})$ behavioral intentions (BI).

\section{METHOD}

\section{Sample}

A sample of 154 students from a West Australian university participated in the experiment in return for a free large pizza voucher. The homogeneity of the sample in terms of demographics and familiarity with computer equipment increased the internal validity of this exploratory research. Both genders were evenly represented (52 percent females, 48 percent males). The mean age was 21 years $(S D=$ 5.1 years). Most participants had at least one television at home $(M=2$, range $=0$ to 6) and watched TV on average from one to three hours a day. Only 23 participants (15 percent) had access to Pay TV (this compared to a national average of 21 percent in Australia at the time), but 55 (36 percent) owned at least one DVD player. 


\section{Procedures}

Four product categories were selected from six candidate categories identified by Hawthorne (1997) as best suited to the infomercial format, following a pilot study that measured the product category involvement of a representative sample of 12 students. The four categories, chosen to generate the widest possible variation in levels of product category involvement among students (and their representative brands), were charity organizations (World Vision), exercise equipment (Total Gym), snack foods (PowerBar), and prestige cars (BMW). The advertisements used had been professionally produced, and all except PowerBar had either been aired or tested by advertising agencies. Random assignment to experimental conditions was used to control for possible effects of advertising familiarity.

Instead of using actual PVRs, the functionality of PVRs was imitated by the use of a digital versatile disc (DVD) player (Bezjian-Avery, Calder, and Iacobucci, 1998; Hughes, 1992). All participants viewed a 30-minute television presentation ("Better Homes and Gardens") with four advertising breaks. Each advertising break consisted of a group of filler advertisements (to create a standard length commercial break) followed by one experimental advertisement shown in the last position in the break (standard practice for interactive advertisements). Participants were randomly allocated to one of three conditions. Participants in the telescopic advertising format condition $(n=70)$ were instructed that if a "telescope" logo appeared in the bottom right-hand corner of the last 30-second advertisement in an advertising break, clicking on that logo would access additional advertising content. A short text description of this content and its duration scrolled across the bottom of the screen twice before the 30 second (level-1) advertisement ended. For the purposes of this experiment, participants who clicked to view this additional (level-2) content were forced to view the entire duration of this content before returning to the beginning of the program following the advertising break (this was achieved by locking the navigation controls during the level-2 content). This additional content was in the form of an infomercial, which varied by advertisement in duration from 2 minutes, $12 \mathrm{sec}$ onds to 6 minutes, 49 seconds. Clickthrough rates averaged 59 percent (Total Gym was 39 percent; World Vision, PowerBar, and BMW all were 66 percent). Participants who saw the level-1 advertisement only ( $n=42$ ) just saw the level-1 content (the 30-second advertisement), while participants who saw the level-2 advertisement only $(n=42)$ saw just the level-2 content (the long-form infomercial). Order of presentation of the experimental advertisements was rotated across participants to control for order effects. There were no significant differences in click-through rates across the four random orders used (55 percent, 55 percent, 63 percent, 61 percent; $\chi^{2}(3)=1.47$, ns).

Before viewing the advertising content, participants completed a short survey measuring their product category involvement in the four test categories. After viewing the 30 -minute TV presentation, participants completed an additional survey that measured their demographics and responses on the experiment's dependent variables.

\section{Measures}

Product category involvement. Participants were asked to rate their level of involvement for each of the four product categories represented by the four advertised brands before watching the test program. Ideally, the sensitization effect of asking these questions would have been minimized, either by collecting these mea- sures several weeks beforehand, or by collecting measures for filler categories as well. But this sensitization effect was equally distributed across all three advertising formats and tends to make our results more conservative. Five 7-point semantic differential items were used, based on items from the Personal Involvement Inventory (PII: Zaichkowsky, 1985) and the Purchase-Decision Involvement scale (PDI: Mittal, 1989): importantunimportant, of no concern to me-of concern to me, means a lot to me-means nothing to me, does not matter to me-matters to me, and significant-insignificant. After recoding, higher scores indicated higher product category involvement $(\alpha=.81$ [charity organizations, $M=5.60$ ], .94 [exercise machines, $M=3.15$ ], .94 [snack foods, $M=$ 4.32], and .94 [prestige cars, $M=3.72$ ]; $\alpha$ was above 7 for all four categories [Nunnally and Bernstein, 1994] and all four means differed significantly from each other [Tukey HSD test, $p<.05]$ ).

Attitude toward the advertisement $\left(\mathrm{A}_{\mathrm{ad}}\right)$ was measured using nine 7 -point semantic differential scales, also based on items from the PII and the PDI: good-bad, interesting-not interesting, appealing-not appealing, attractive-not attractive, dulldynamic, likable-not likable, pleasantunpleasant, depressing-refreshing, and enjoyable - not enjoyable. Again, after recoding, higher numbers indicated a more favorable attitude ( $\alpha=.86$ [World Vision], .93 [Total Gym], 94 [PowerBar], and .94 [BMW]).

Attitude toward the brand $\left(\mathrm{A}_{\mathrm{b}}\right)$ was measured with five 7-point semantic differential items: good-bad, pleasant-unpleasant, useful-useless, awful-nice, and importantunimportant ( $\alpha=.86$ [World Vision], .88 [Total Gym], .89 [PowerBar], and .82 [BMW]).

Behavioral intentions (BI) were measured with three 7-point semantic differential items $(1=$ yes definitely to $7=$ definitely 
not) that differed across the four products. For the World Vision advertisement, the BI items were: "Would you like to be a volunteer for WORLD VISION at some time?", "Would you be interested in receiving more information about WORLD VISION?", and "Would you recommend the WORLD VISION organization to a friend?" The last two of these behaviors, receiving more information and recommending the brand to a friend, did not differ across brands. The corresponding first items for the other three brands were: "Would you like to try out the TOTAL GYM?", "Would you like to sample a POWERBAR?", and "Would you like to test drive a BMW?" $(\alpha=.78$ [World Vision], .84 [Total Gym], .77 [PowerBar], and .71 [BMW]).

Demographic control variables. Finally, the survey asked a number of demographics questions that were possible covariates in the analysis: gender, age in years, number of televisions in the home, "Do you have Pay TV in your home?" (yesno), number of DVD players in the home, and number of hours of television watched on an average daily basis (6-point scale: $1=$ less than 1 hour to $6=$ more than 9 hours).

\section{Analysis}

A repeated measures dataset was created by stacking responses to the four advertisements from each participant. Because the same telescopic condition participant could be an interactor for one advertisement and a noninteractor for another advertisement, we tested whether the residuals from the repeated observations for participants were independent (uncorrelated). The Durbin-Watson statistics for this test were insignificant for all three dependent variables $\left(\mathrm{A}_{\mathrm{ad}}=1.80, \mathrm{~A}_{\mathrm{b}}=\right.$ 1.92 , and $\mathrm{BI}=1.85$, all $>1.78$, the critical upper limit for the Durbin-Watson statis- tic with $N>100$ and number of parameters $>5$ ). Further evidence for confidence in the assumption of independence between observations was the fact that there were no differences on any of the three dependent variables among those who interacted with one telescopic advertisement ( $n=14,20$ percent), two $(n=24,34$ percent), three ( $n=20,29$ percent), or all four $(n=12,17$ percent; $M=2.4$; Wilks' $\Lambda=.94, F(9,660)=1.77$, ns $)$. The repeated measures dataset was analyzed using multivariate analysis of covariance (MANCOVA), controlling not only for the hypothesized effects of product category involvement, but also for differences between brands (which could have been due to, for example, execution, familiarity, etc.), and for differences in demographics between groups. There were significant differences between groups in terms of gender, age, number of TV sets, and whether there was a DVD player in the home.

\section{FINDINGS}

First, we report the differences in the raw data between the groups, without controlling for differences in covariates such as product category involvement (Figure 1). Confirming Hypothesis H1, participants who interacted with telescopic advertisements had significantly higher scores, averaged across all four product categories, for attitude toward the advertisement $\left(A_{a d}\right)$, attitude toward the brand $\left(A_{b}\right)$, and $\mathrm{BI}$, compared to all three other groups: noninteractors, and participants who saw either the level-1 (traditional 30-second) advertisement or the level-2 (long-form infomercial) advertisement (Wilks' $\Lambda=.91$, $F(9,1,485)=6.28, p<.001 ; \mathrm{A}_{\mathrm{ad}} F(3,612)=$ 14.87, $\mathrm{A}_{\mathrm{b}} F(3,612)=8.67$, and $\mathrm{BI}$ $F(3,612)=15.75$, all $p<.001)$. Reinforcing

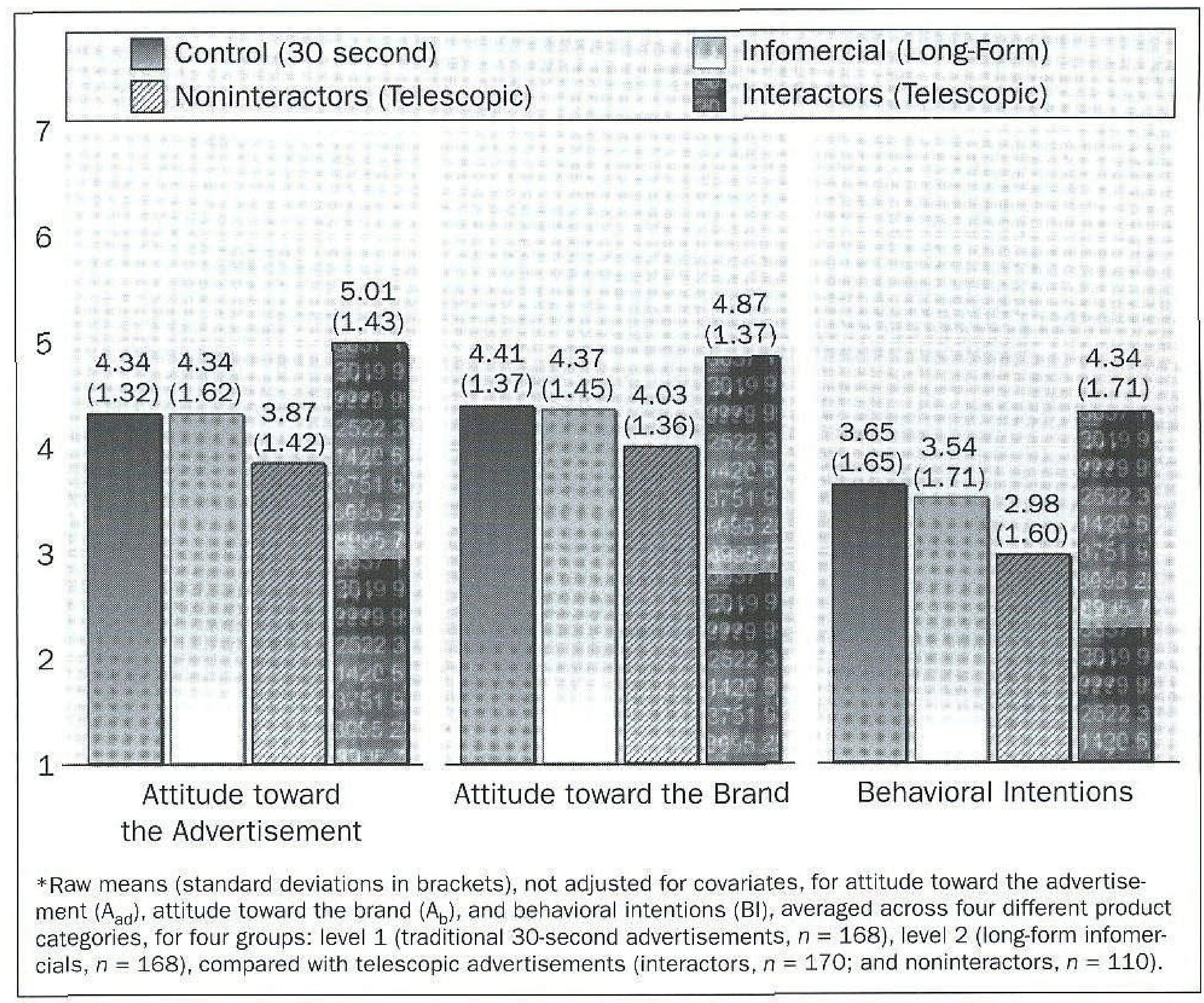

Figure 1 Raw Data between the Groups* 
these comparisons among means, which can be subject to distributional biases (Rossiter and Bellman, 2005), there was a significant lift on the practitioners' measure, "top-box" behavioral intentions (the percentage checking 6 on a 7 -point scale or higher, on average, for the three behavioral intentions items), when telescopic interactors were compared with the other three groups (telescopic interactors = 23 percent, telescopic noninteractors $=4$ percent, level $1=12$ percent, level $2=12$ percent; $\chi^{2}(3)=22.91, p<.001$ ). This 92 percent lift compared to both traditional advertising formats, however, was artifi- cially inflated because of the semiforced nature of our experiment, which generated a very high 59 percent click-through. In particular, the difference between interactors and noninteractors in these raw data would be mainly due to self-selection effects, in which those most interested in the advertised product interacted, and those who were not interested did not. In the main analyses reported below we control for this self-selection effect. Even with three-fifths of our sample interacting, however, the impact of telescopic advertisements was not superior to other formats when interactors and noninteractors were combined together (Wilks' $\Lambda=.99$, $F(6,1,222)=.68, p=.663)$.

Table 1 lists the results of the MANCOVA analyses for the three dependent variables. There was a significant multivariate effect of advertising format (Wilks' $\Lambda=.93, F(9,1,458)=4.55, p<.001)$. Consistent with Hypothesis H1, the means for the telescopic interactors were significantly higher than the means for the level-1 and level-2 advertising formats, and also higher than the means for noninteractors (all $p<.001$ for $A_{\text {ad }}$, all $p<.05$ for $A_{b}$, and all $p<.01$ for $\mathrm{BI}$, after Bonferroni correction for multiple comparisons). The

\section{TABLE 1}

The Effect of Advertising Format on Advertising Effectiveness

Means (1-7) (Standard Errors)

Level 1

\begin{tabular}{|c|c|c|c|c|c|c|c|}
\hline $\begin{array}{l}\text { Dependent } \\
\text { Variable }\end{array}$ & Effect & F-Ratio & $\begin{array}{l}\text { Significance } \\
\text { Level }\end{array}$ & $\begin{array}{l}\text { (30-second } \\
\text { Advertisement) }\end{array}$ & $\begin{array}{l}\text { Level } 2 \\
\text { (Infomercial) }\end{array}$ & $\begin{array}{l}\text { Telescopic } \\
\text { (Noninteractors) }\end{array}$ & $\begin{array}{l}\text { Telescopic } \\
\text { (Interactors) }\end{array}$ \\
\hline \multirow[t]{4}{*}{$A_{\text {ad }}$} & Format & 10.53 & $<.001$ & $\begin{array}{r}4.34 \\
(.09)\end{array}$ & $\begin{array}{l}4.35 \\
(.09)\end{array}$ & $\begin{array}{l}4.17 \\
(.11)\end{array}$ & $\begin{array}{c}4.88 * \\
(.09)\end{array}$ \\
\hline & Brand & 128.54 & $<.001$ & & & & \\
\hline & Involvement & 11.69 & .001 & & & & \\
\hline & Format $\times$ involvement & 3.07 & .027 & & & & \\
\hline \multirow[t]{4}{*}{$A_{b}$} & Format & 4.03 & .007 & $\begin{array}{l}4.37 \\
(.09)\end{array}$ & $\begin{array}{l}4.39 \\
(.08)\end{array}$ & $\begin{array}{l}4.32 \\
(.11)\end{array}$ & $\begin{array}{l}4.71^{*} \\
(.08)\end{array}$ \\
\hline & Brand & 89.03 & $<.001$ & & & & \\
\hline & Involvement & 47.28 & $<.001$ & & & & \\
\hline & Format $\times$ involvement & .20 & .899 & & & & \\
\hline \multirow[t]{4}{*}{$\mathrm{BI}$} & Format & 8.77 & $<.001$ & $\begin{array}{r}3.62 \\
(.10)\end{array}$ & $\begin{array}{r}3.57 \\
(.10)\end{array}$ & $\begin{array}{r}3.33 \\
(.13) \\
\end{array}$ & $\begin{array}{c}4.13 * \\
(.10)\end{array}$ \\
\hline & Brand & 87.05 & $<.001$ & & & & \\
\hline & Involvement & 77.35 & $<.001$ & & & & \\
\hline & Format $\times$ involvement & .37 & .772 & & & & \\
\hline
\end{tabular}

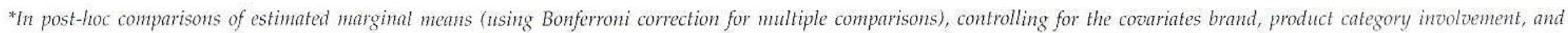

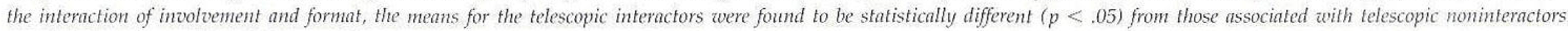

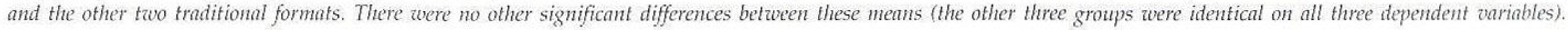


means reported in Table 1 are leastsquares means controlling for the effects of other variables in the model, including the hypothesized effects of product category involvement, as well as differences between brands and demographic differences between participants (discussed below).

There was a significant multivariate effect of product category involvement $\left(\right.$ Wilks $^{\prime} \Lambda=.88, F(3,599)=28.07, p<$ $.001)$, consistent with Hypothesis H2. Product category involvement was positively associated with two of the three dependent variables $\left(\mathrm{A}_{\mathrm{b}} \beta=.22, S E=.064, p<\right.$ .001 and $\mathrm{BI} \beta=.30, S E=.064, p<.001$ ). For $A_{a d}$, however, involvement had no effect after controlling for differences between brands $(\beta=-.002, S E=.063, p=$ .973). The inclusion of involvement as a covariate (along with the other covariates) has eliminated the self-selection effect: the adjusted mean for the noninteractors was now no different from the means for the other two control groups (see Table 1).

Hypothesis H3 predicted that telescopic advertisements would also outperform the other two formats for participants with low product category involvement, as the lab conditions would have encouraged them to watch additional content they would not ordinarily be interested in. Contrary to Hypothesis $\mathrm{H} 3$, the multivariate effect of the interaction between product category involvement and advertising format was insignificant (Wilks' $\Lambda=$ $.98, F(9,1,458)=1.32, p=.224)$, after controlling for the main effect of product category involvement and other covariates. What this means is that the superior effects for interaction with telescopic advertisements that we report cannot be explained by the inclusion of data from lowinvolvement participants who would be very unlikely to interact with telescopic advertisements in their home environment.

\section{Telescopic advertisements can be more effective than}

\section{traditional advertisements, both 30 -second advertise- ments and long-form infomercials.}

As we reported above in the section on measuring product category involvement, there were significant differences in mean involvement between the four brands. The means listed in Table 1 control for a significant covariate effect of brand (Wilks' $\Lambda=.38, F(9,1,458)=79.73, p<.001)$. The other significant covariate was gender (Wilks' $\Lambda=.98, F(3,599)=4.07, p=.007)$. Males tended to have more favorable attitude toward the advertisement and behavioral intentions than females (males versus females: $\mathrm{A}_{\mathrm{ad}} M=4.58$ versus 4.29 , $p=.002$; BI $M=3.77$ versus $3.55, p=$ .045).

When data from individual brands were analyzed separately, the results generally replicated the results for the overall data set, although the smaller data sets and range restrictions meant that telescopic advertisements were not always significantly superior for some of the brands. Telescopic interactors had a more favorable $\mathrm{A}_{\mathrm{ad}}$ than noninteractors and those who saw level-1 advertisements only, for BMW $(M=6.36$ versus noninteractors $M=4.94, p<.001$; versus level $1 M=$ $5.30, p<.001)$ and Total Gym $(M=3.97$ versus noninteractors $M=3.04, p=.015$; versus level $1 M=2.86, p=.002$ ). Telescopic interactors were also associated with superior effects on BI compared to noninteractors, for Total Gym $(M=3.21$ versus $M=2.07, p=.014$ ), compared to noninteractors and those who just saw the level-1 advertisement for BMW $(M=5.47$ versus noninteractors $M=4.30, p<.001$; versus level $1 M=4.79, p=.018$ ), and compared to those who saw only the level-1 adver- tisement or the level-2 advertisement for PowerBar $(M=3.79$ versus level $1 M=$ $2.94, p=.023$; versus level $2 M=2.96, p=$ $.028)$.

As we reported above in the Procedure section, the rate of click-through for the Total Gym advertisement was significantly lower than the rate for the other three brands ( 39 percent versus 66 percent; $\chi^{2}(3)=14.99, p=.002$ ). This low rate of click-through was probably due to relatively unappealing nature of the level-1 portion of the Total Gym advertisement compared to all three other brands (Total Gym $\mathrm{A}_{\mathrm{ad}} M=3.06$ versus World Vision $M=4.35, p<.001$; PowerBar $M=4.72$, $p<.001$; and BMW $M=5.41, p<.001$ ).

\section{DISCUSSION}

The results of this preliminary investigation suggest that telescopic advertisements can be more effective than traditional advertisements, both 30 -second advertisements and long-form infomercials. In general, the telescopic advertising format was the best performer in terms of three generally used measures of advertising effectiveness: attitude toward the advertisement, attitude toward the brand, and behavioral intentions toward the brand, even after controlling for the self-selection effect of product category involvement.

According to the dual mediation hypothesis (Lutz, MacKenzie, and Belch, 1983), positive advertising attitude influences brand attitude directly (Mitchell and Olson, 1981), and indirectly (by generating positive brand cognitions), and brand attitude has a direct influence on behavioral 
intentions toward the brand (Brown and Stayman, 1992). All these variables are positively correlated in our study (Table 2). The interrelationship of these variables also suggests that if advertisers can motivate consumers to interact with telescopic advertisements, their ability to create more favorable advertising attitude could generate more purchasing than traditional advertising formats.

This general finding of superiority for the telescopic format was qualified by some insignificant results in some product categories. For the charity advertisement, there were no differences across formats on any of the advertising effectiveness measures. Because this category also had the highest level of involvement, these null results may reflect a ceiling effect. Also, for this category, responses to the advertising effectiveness measures may have been affected by social desirability bias. But in no case was the pattern of means opposite to the general direction: telescopic advertisements were always equal to, if not better than, the other two formats. We had only one advertisement from just four product categories, however, so we cannot say for sure whether telescopic advertisements work better for some products and not for others.
Because the number of interactors with telescopic advertisements is always likely to be less than the entire audience, we expected that telescopic advertisements would not be superior to traditional advertisements when interactors and noninteractors were aggregated together, and that is what we found. This requirement for interaction restricts the utility of interactive advertisements (Rosenfield, 1997). In particular, they are not suitable for raising public awareness quickly (for example, in a product recall or health alert campaign). For this purpose, 30-second advertisements remain supreme. Also, there is always the danger that inferior additional content will fail to match the promise of the motivating 30-second commercial, and this could generate even greater emotional backlash and cognitive counterargument than if the advertisement had not been interactive.

The early evidence from this study suggests, however, that like all direct response advertisements, telescopic advertisements move prospects one stage closer to buying and even to completing the transaction, and for this reason they could be highly profitable in terms of ROI (Harvey, 2004). Clearly, though, a major challenge for advertisers adopting this new

\section{TABLE 2}

\section{Correlations between Product Category Involvement and Several Advertising-Related Variables, Across Four Product Categories*}

\begin{tabular}{|c|c|c|c|c|}
\hline & Involvement & $A_{a d}$ & $A_{b}$ & BI \\
\hline Involvement & $-\ldots \ldots$ & & & \\
\hline$A_{a d}$ & $.14 * *$ & $-\ldots$. & & \\
\hline$A_{b}$ & $42 * *$ & $.58 * *$ & $-\ldots$ & \\
\hline $\mathrm{BI}$ & $.37 * *$ & $.63 * *$ & $.73 * *$ & $-\ldots$ \\
\hline
\end{tabular}

*Correlations that are significant at or below the 0.01 level (2-tailed) are symbolized by double asterisks. Correlations that are significant at or below the 0.05 level (2-tailed) are symbolized by single asterisks. model is motivating consumers to interact with TV advertisements, especially if viewers are in a passive, "leaning back" mode of TV viewing (Barwise, 2001), or they are using their PVRs to actively avoid advertisements (Dignam, 2000; Harmon, 2002; Krugman, 1988; Olney, Holbrook, and Batra, 1991; Tse and Lee, 2001). It is likely, however, that the same triggers that generate responses in other media, such as calls to action ("click here!" or "phone now"), incentives (e.g., competitions, samples), and "random" differences in execution (e.g., Drèze and Hussherr, 2003), will also be important for advertisers attempting to maximize click-through for telescopic advertisements. Also, by using direct matching (Rossiter and Bellman, 2005) to target advertisements at viewers with high product category involvement, media planners can maximize interaction rather than repetition. This reflects growing demands from industry for the delivery of audience "engagement" rather than "exposure" alone (MPA, 2006). This task may become easier in the future as "addressable" set-top boxes continue to deploy across both cable and satellite platforms.

\section{Limitations}

This study had a number of limitations, which suggest our findings may not replicate outside our laboratory. Unlike real telescopic advertisements, our participants did not have the ability to "click out" of our additional telescopic content. This forced exposure to the entirety of the additional telescopic content perhaps biased our results compared to what might be achieved with telescopic advertisements in real living rooms.

Furthermore, interaction (clicking for content) may put viewers in a "lean forward" mode of processing in which more attention is paid (e.g., Barwise, 2001; Rosenfield, 1997). This would explain the superior persuasive effect of telescopic 
advertisements in our experiment, even though the amount of information in the infomercial and the telescopic advertisements was substantially the same. The artificial nature of our lab environment may have encouraged interaction from participants with a very low probability of doing so at home.

People who have watched additional content once may be less likely to do so again. This would be a concern if multiple exposures to the additional content were required to achieve minimum effective frequency. It remains to be seen, in further research, the extent that the effectiveness of the interactive/telescopic advertisement is a function of novelty or the forced nature of our procedure, or whether a substantial proportion of TV viewers will continue to click through to view further information.

Another limitation of this study is the use of a student sample, collected in Australia. As PVRs and telescopic advertisements become more pervasive, future researchers will be able to confirm our findings using samples representative of the total television audience, and in other countries, viewing telescopic and other advertisements at home.

\section{CONCLUSIONS}

The purpose of the experiment reported here was to determine if the use of telescopic advertisements, a new type of TV advertising format made possible by PVRs, could make a significant difference to advertising effectiveness. Although subject to replication with different samples and commercials, our results suggest that, provided they are interacted with, telescopic advertisements have significantly positive effects on attitude toward the advertisement, attitude toward the brand, and behavioral intentions, compared to traditional 30-second advertisements and longform infomercials. Far from representing

\section{Far from representing the "death" of television commer- cials, the PVR potentially introduces new models of advertising.}

the "death" of television commercials, the PVR potentially introduces new models of advertising that may potentially enhance the television landscape. Better understanding these new models remains an important area for continuing research. Aip

Nicholas Reading holds a Bachelor of Marketing and the Media with First Class Honours from Murdoch University, Australia. After completing his studies, Nicholas joined the mining company, Rio Tinto, where he currently focuses on executing emerging market supply opportunities.

Steven Bellman (Ph.D., University of New South Wales) is an associate professor and deputy director of the Interactive Television Research Institute, Murdoch University, Australia. His main research interest is interactive advertising and marketing.

DuANE VARAN (Ph.D., University of Texas at Austin) is executive director of the Interactive Television $\mathrm{Re}$ search Institute at Murdoch University. Prof. Varan is the recipient of numerous awards including the Australian Prime Minister's University Teacher of the Year Award (2001) and the Australian Award for University Teaching in Economics, Business and Related Studies (2001).

Hume WinzaR is a senior lecturer in marketing at Griffith University, Brisbane, Australia. His research interests focus on the nature of business functions as a result of changes to interactive technology, consumer preference modeling, and brand share forecasting methods.

\section{REFERENCES}

Agee, Tom, and Brett A. S. Martin. "Planned or Impulse Purchases? How to Create Effective Infomercials." Journal of Advertising Research 41, 6 (2001): 35-42.

Ajzen, ICeK, and Martin Fishbein. "AttitudeBehavior Relations: A Theoretical Analysis and Review of Empirical Research." Psychological Bulletin 84, 5 (1977): 888-918.

Baron, Reuben M., and David A. Kenny. "The Moderator-Mediator Variable Distinction in Social Psychological Research: Conceptual, Strategic, and Statistical Considerations." Journal of Personality and Social Psychology 51, 6 (1986): $1173-82$.

Barwise, Patrick. "TV, PC, or Mobile? Future Media for Consumer e-Commerce." Business Strategy Review 12, 1 (2001): 35-42.

Bezjian-Avery, Alexa, Bobby Calder, and Dawn IAcobucci. "New Media Interactive Advertising vs. Traditional Advertising." Journal of Advertising Research 38, 4 (1998): 23-32.

Biel, Alexander L., and Carol A. BridgWATER. "Attributes of Likable Television Commercials." Journal of Advertising Research 30, 3 (1990): 38-44.

Blair, Margaret H., and Michael J. Rabuck. "Advertising Wearin and Wearout: Ten Years Later-More Empirical Evidence and Successful Practice." Journal of Advertising Research 38, 5 (1998): 7-18. 
Brown, Steven P., and Douglas M. Stayman. "Antecedents and Consequences of Attitude toward the Ad: A Meta-Analysis." Journal of Consumer Research 19, 1 (1992): 34-51.

Buchholz, Laura M., and Robert E. Smith. "The Role of Consumer Involvement in Determining Cognitive Response to Broadcast Advertising." Journal of Advertising 20, 1 (1991): 4-17.

Celsi, Richard L., and Jerry C. Olson. "The Role of Involvement in Attention and Comprehension Processes." Journal of Consumer Research 15, 2 (1988): 210-24.

Chapman, Patricia S., and Richard F. BelTRAMINI. "Infomercials Revisited: Perspectives of Advertising Professionals." Journal of Advertising Research 40, 5 (2000): 24-31.

Dignam, Conor. "New Technology is Placing the Future of TV Ads in Doubt." Marketing (London), October 5, 2000.

Drèze, Xavier, and François-Xavier HussHERR. "Internet Advertising: Is Anybody Watching?" Journal of Interactive Marketing 17, 4 (2003): 8-23.

Du Plessis, ERIK. "Recognition versus Recall." Journal of Advertising Research 34, 3 (1994): 75-91.

Festinger, Leon. A Theory of Cognitive Dissonance. Evanston, IL: Row, Peterson \& Co., 1957.

Friedman, Wayne. "PVR Users Skip Most Ads: Study." Advertising Age, July 1, 2002.

Gibson, Lawrence D. "Not Recall." Journal of Advertising Research 23, 1 (1983): 39-46.

HA, Loursa, and E. Lincoln James. "Interactivity Reexamined: A Baseline Analysis of Early Business Web Sites." Journal of Broadcasting $\mathcal{E}$ Electronic Media 42, 4 (1998): 457-74.
Harmon, Amy. "Skip-the-Ads TV Has Madison Ave. Upset." New York Times, May 23, 2002.

Harmon-Jones, Eddie, and Judson Mills. Cognitive Dissonance: Progress on a Pivotal Theory in Social Psychology. Washington, DC: American Psychological Association, 1999.

Harvey, Bill. "Better Television Audience Measurement through the Research Integration of Set-Top Box Data. Phase Two." Conference Paper. Worldwide Audience Measurement (WAM) 2004. Amsterdam, The Netherlands: ESOMAR/ ARF, 2004.

Hawthorne, Timothy R. The Complete Guide to Infomercial Marketing. Lincolnwood, IL: NTC Publishing Group, 1997.

Higie, Robin A., Lawrence F. Feick, and Linda L. PrICE. "The Importance of Peripheral Cues in Attitude Formation for Enduring and Task Involved Individuals." Advances in Consumer Research 18 (1991): 187-93.

Hughes, G. David. "Realtime Response Measures Redefine Advertising Wearout." Journal of Advertising Research 32, 3 (1992): 61-77.

Krugman, Herbert E. "Point of View: Limits of Attention to Advertising." Journal of Advertising Research 28, 5 (1988): 47-50.

Lutz, Richard J., Scott B. MacKenzie, and George E. Belch. "Attitude toward the Ad as a Mediator of Advertising Effectiveness: Determinants and Consequences." Advances in Consumer Research 10 (1983): 532-39.

McMillan, Sally J., Jang-Sun Hwang, and Guiohk Lee. "Effects of Structural and Perceptual Factors on Attitudes toward the Website." Journal of Advertising Research 43, 4, (2003): $400-9$.
Mitchell, Andrew A., and Jerry C. Olson. "Are Product Attribute Beliefs the Only Mediator of Advertising Effects on Brand Attitude?" Journal of Marketing Research 18, 3 (1981): 318-32.

Mittal, Banwari. "Measuring PurchaseDecision Involvement." Psychology and Marketing 6, 2 (1989): 147-62.

MPA. Engagement: Understanding Consumers' Relationships with Media. New York, NY: Magazine Publishers of America, 2006: [URL: http:/ /www.magazine.org/engagement], accessed July 20, 2006.

Nunnally, Jum C., and Ira H. Bernstein. Psychometric Theory, 3rd ed. New York: McGrawHill, 1994.

Oliver, Richard L. Satisfaction: A Behavioral Perspective on the Consumer. New York: McGrawHill, 1997.

Olney, Thomas J., Morris B. Holbrook, and Rajeev Batra. "Consumer Responses to Advertising: The Effects of Ad Content, Emotions, and Attitude toward the Ad on Viewing Time." Journal of Consumer Research 17, 4 (1991): 440-53.

Olsen, S., and R. Shim. "Tivo Looks to Tune in to Advertisers." CNET News, March 23, 2004: [URL: http://news.com.com/TiVo+looks + to + tune + in + to + advertisers /2100-1041_3-5178017. html], accessed May 1, 2006.

Petty, Richard E., John T. Cacioppo, and David Schumann. "Central and Peripheral Routes to Advertising Effectiveness: The Moderating Role of Involvement." Journal of Consumer Research 10, 2 (1983): 135-46.

Richins, Marsha L., and Peter H. Bloch. "After the New Wears Off: The Temporal Context of Product Involvement." Journal of Consumer Research 13, 2 (1986): 280-85. 
Rosenfield, James R. "From the Practitioners: Advertising and "Interactive Marketing": Why the Twain Can't Meet." Journal of Direct Marketing, 11, 2 (1997): 2-3.

Ross, Harold L., JR. "Recall versus Persuasion: An Answer." Journal of Advertising Research 24, 4 (1984): 55-58.

Rossiter, John R., and Steven Bellman. Marketing Communications: Theory and Applications. Frenchs Forest, NSW, Australia: Pearson/ Prentice Hall, 2005.

and Geoff Eagleson. "Conclusions from the ARF's Copy Research Validity Project." Journal of Advertising Research 34, 3 (1994): 19-32.

Shultz, Thomas R., Elène Léveillé, and Mark R. Lepper. "Free Choice and Cognitive Dissonance Revisited: Choosing 'Lesser Evils' Versus 'Greater Goods.'" Personality \& Social Psychology Bulletin 25, 1 (1999): 40-48.

Singh, Mandeer, Siva K. Balasubramanian, and Goutam Chakraborty. "A Comparative Analysis of Three Communication Formats: Ad- vertising, Infomercial, and Direct Experience." Journal of Advertising 29, 4 (2000): 59-75.

Singh, Surendra N., and Catherine A. Cole. "The Effects of Length, Content, and Repetition on Television Commercial Effectiveness." Journal of Marketing Research 30, 1 (1993): 91-104.

Stanton, John L., and Jeffrey Burke. "Comparative Effectiveness of Executional Elements in TV Advertising: 15- versus 30-second Commercials." Journal of Advertising Research 38, 6 (1998): 7-14.

Stewart, David W. "The Moderating Role of Recall Comprehension and Brand Differentiation on the Persuasiveness of Television Advertising." Journal of Advertising Research 26, 2 (1986): 43-47.

Sutherland, Max, and Alice K. Sylvester. Advertising and the Mind of the Consumer: What Works, What Doesn't, and Why, 2nd ed. St. Leonards, NSW, Australia: Allen \& Unwin, 2000.

Swain, Philip, and Andy Blustin. "Personal Television Services: The Impact on Advertis- ers." White Paper, London, UK: Decipher, November 2000: [URL: http://www.decipher. co.uk/], last accessed January 7, 2004.

Terry, Deborah J., and Joanne E. O'Leary. "The Theory of Planned Behaviour: The Effects of Perceived Behavioural Control and SelfEfficacy." British Journal of Social Psychology 34, 2 (1995): 199-220.

Tse, Alan Ching Biu, and Ruby P. W. Lee. "Zapping Behavior during Commercial Breaks." Journal of Advertising Research 41, 3 (2001): 25-29.

Vaughn, Richard. "How Advertising Works: A Planning Model Revisited." Journal of Advertising Research 26, 1 (1986): 57-66.

Walker, David, and Tony M. Dubitsky. "Why Liking Matters." Journal of Advertising Research 34, 3 (1994): 9-18.

ZAICHKOWSKY, JUDITH L. "Measuring the Involvement Construct." Journal of Consumer Research 12, 3 (1985): 341-52. 